\title{
An Expectancy-Value Approach to the Study of Beliefs Underlying Consumer Boycott Intention
}

\author{
Maya F. Farah ${ }^{1}$ \\ ${ }^{1}$ School of Business, Lebanese American University, Lebanon \\ Correspondence: Maya F. Farah, School of Business, Lebanese American University, Lebanon. E-mail: \\ mfarah@lau.edu.lb
}

Received: June 17, 2014

Accepted: August 1, 2014

Online Published: September 25, 2014

doi:10.5539/ijbm.v9n10p101

URL: http://dx.doi.org/10.5539/ijbm.v9n10p101

\begin{abstract}
In order to (a) investigate the expectancy-value model supporting the beliefs behind boycott intentions in the theory of planned behaviour, and (b) to identify the specific beliefs that could be used as targets in counter-boycott participation interventions, this paper adopts a socio-cognitive approach to examine the beliefs underpinning consumers' boycott intention. A randomized systematic sample of 500 respondents completed a questionnaire measuring both the indirect and direct TPB variables with respect to boycotting. The statistical results confirmed the validity of the expectancy-value principle in the TPB. By delineating the beliefs that were statistically significant predictors of direct TPB measures and intention, the study identified belief targets that can be utilized to develop countermeasures persuading consumers not to boycott American companies in the Arab World. This application of a socio-psychological theory to consumers' boycott behaviour yielded significant contributions both at the empirical and the managerial levels.
\end{abstract}

Keywords: boycott intention, theory of planned behaviour, expectancy value approach

\section{Introduction}

Whether boycotted for their acting against human rights, the environment, or animal rights, companies increasingly face the risks of consumers voting through their wallets for the type of societies they want to live in. By withholding their buying from companies or countries that they perceive as abusive, consumers expect to increase corporate and governmental sensitivity to their economic, environmental, political and social concerns (Sen, Gurhan-Canli, \& Morwitz, 2001). As a result of the high incidence of consumers' organized boycott campaigns, and since boycotts negatively affect the target company's reputation, sales, and stock price (Davidson, Worrell, \& El-Jelly, 1995) the question of what motivates consumers to join boycotts became a growing concern for research. Nevertheless, extant research related to the motivation of consumers to participate in a boycott has largely been either conceptual or case descriptive concentrating in most instances on boycott targets (Klein, Smith, \& John, 2004) and the consequences of boycotts on corporate image and financial performance (Pruitt \& Friedman, 1986; Pruitt, White, \& Wei, 1988). Only a few attempts have been undertaken focusing directly on the individual motivations of consumers within a socio-psychological framework (e.g., Klein et al., 2004; Sen et al., 2001; Smith, Klein, \& John, 2003).

This research studies the case of an indirect boycott, whereby the targeted firms are surrogates for the party whose actions are objectionable. The paper tackles a macro-boycotting case, where American companies pay the price for a political crisis of which they are not principally responsible. In fact, boycotts of American products have been conducted by numerous Arab civilians in the past couple of decades as a sign of protest against the US policy in the Middle East (Al- Zobaidy, 2002). The sheer fact that 300 million Arab consumers could be reached and persuaded, even partially, to boycott American goods has been a cause of concern for many potentially targeted US companies.

This paper extends a socio-cognitive approach to understand the mechanisms by which Lebanese consumers' behavioural intention to boycott American products are influenced. The TPB (Ajzen 1991), which typically provides an outstanding account of behaviour in social psychology, is believed to have much to offer in the development of counteractive measures against consumers' intention to participate in a boycott. Accordingly, this study was conducted to: (a) test the expectancy-value theory (EVT, Fishbein \& Ajzen, 1975) supporting the beliefs behind boycott intentions, and (b) to identify the specific beliefs that could be used as targets in 
counter-boycott interventions.

\section{Consumer Boycott Motivations}

A boycott describes "the attempt by one or more parties to achieve certain objectives by urging individual consumers to refrain from making selected purchases in the marketplace" (Friedman, 1999a, p. 4). Numerous micro-boycotting motives discussed in the literature may be significant in the conceptualization of the drives motivating individual consumers' participation in macro-boycotting campaigns. Research suggests that the perceived egregiousness of an entity's actions is the principal reason for boycott motivation (Smith, 1990). Klein, Ettenson and Morris (1998) tackle this behaviour at a macro-level where a country's policies lead to a boycott of all products from that country. The egregious act in such situations is not committed by the target itself. Partaking in a boycott called for by a group with which one associates firmly is a common way of relating to popular attitudes and moral values. One may choose to join the campaign merely to satisfy the need for group belongingness, provided that one's self-concept derives partly from that group (Tajfel, 1982). Boycott participation can also be motivated by one's need for anger expression, for self-esteem maintenance or self-esteem enhancement (Brewer \& Brown, 1998; Klein, Smith \& John, 2002; Pittman, 1998). Though much of the literature refers to participating in boycotts as a social activity, this behaviour may also be 'the expression of an individual uniqueness' motivated by a drive for moral self-realization (Sen et al., 2001). In addition, an individual's own feeling of moral obligation is important; indeed, feelings of citizen-efficacy (Tyler \& McGraw, 1983) can be significant drives in this context. Also, an individual's perception that his or her influence can be noteworthy may cause the assumption of a strong relation between one's involvement and the results of the campaign. Besides, led by the thrill of victory, one may like to be part of a successful boycott, in which case both the free-rider and the small-agent effects (Hardin, 1968; Olson, 1965) disappear.

However, the free-rider and small-agent effects can reduce one's incentive to participate. As some people may consider that they would harvest the benefits of a successful boycott regardless of their participation in it, they may be motivated to free-ride upon the actions of others. Besides, many consumers may not be willing to join a boycott campaign as they believe that they are rather insignificant compared to the market and consequently that their actions are unlikely to have any noteworthy influence. Several significant cost-related factors can also restrain one's incentive for boycott participation. As a matter of fact, some potential participants will not boycott if their personal cost related to boycotting is high. In this cost-benefit approach, the first cost is related to consumers' preference and loyalty for the boycotted product (Klein et al., 2004); while the second is associated to the unavailability in the marketplace of suitable and affordable direct substitutes (Sen et al., 2001). Another barrier for participation is the perception that such campaigns may have considerable negative outcomes, such as decreased businesses in the marketplace and increased unemployment (Klein et al., 2004).

\section{Theoretical Framework: the Expectancy-Value Theory Underpinning the TPB}

The TPB, which has been effectively utilised in explaining and predicting a plethora of behaviours (e.g. Elliott, Armitage, \& Baughan, 2003; Lajunen, 2004), is based on the idea that behaviour can be predicted by behavioural intention. According to the TPB, boycott intentions can be determined by: (a) the positive or negative evaluations of boycotting behaviour, in other words, the attitude towards this action, (b) subjective norm, which reflects the perceived social pressure related to boycott participation, and (c) perceived behavioural control (PBC), which depicts the perceived simplicity or complexity of boycotting. Attitudes, SN, and PBC are believed to be based on salient beliefs that interrelate according to the EVT (Eagly \& Chaiken, 1993).

The latter theory proposes that if one can find out the factors that affect intention, then one can more precisely forecast whether an individual will behave in a particular way. Similarly, it suggests that by altering one's perceptions of potential results, one can modify the individual's intention (Borders, Earleywine, \& Huey, 2004). As the level of one's willingness to act in a specific way depends on a) the extent to which the individual believes an outcome will result, and b) the value one places on that outcome (Mazis, Ahtola, \& Kippel, 1975). The more appealing a specific outcome is to the person, the more likely he/she will engage in the behaviour. Likewise, as the number of positive effects increase, the incentive to act in a specific manner will increase.

The application of the TPB in the context of this research entails that attitudes include salient beliefs about the probability of specific results taking place on account of boycotting, and the appraisal of those results. Outcome beliefs and their matching assessments are expected to interrelate, and attitude is believed to be the sum of these belief products. Correspondingly, SN is the sum of salient normative beliefs, which are the multiplications of the beliefs related to the perceived pressure from important individuals to participate in the boycott and the motivation to comply with those opinions. Last, PBC is assumed to be the sum of control belief products, relating to the beliefs of the existence of variables which can hinder or ease boycott participation, and related 
beliefs about the perceived power of these variables. In sum, belief-based measures can be utilised to forecast both their counterpart direct measures and intentions.

The TPB assumes that human beings are inherently rational beings who possess the ability to systematically take account of available information and consider the implications of their actions (Ajzen, 1991) in a reasonable manner, and that one's behavioural intention is the immediate determinant of the action taken, implying that the latter is under the volitional control of the individual. Nonetheless, though people can have various beliefs about a particular behaviour, it is supposed that only beliefs that are easily accessible in memory influence attitude at any given time (Ajzen, 2001).

Moreover, the EVT does not imply that people go through a conscious complex computation; yet, the psychological processes in the human mind entail that the stronger the belief held, and the more positive or negative that belief, the greater is its expected contribution to the attitude. The model also recognizes that beliefs are often affected by cognitive and motivational processes, and that the information retrieval process is commonly distorted by personal convenience (Eagly \& Chaiken, 1993; Fishbein \& Ajzen, 1975). Furthermore, the negativity bias principle explains that "whether cognitive or affective in nature, negative information tends to have a greater impact on overall evaluations than comparably extreme positive information" (Ajzen, 2001).

While the TPB allows the prediction of behavioural intention based on the direct measures of the model, still the key purpose of this study was to investigate its underpinning expectancy value theory. Although the latter has been validated by numerous studies, still there are instances where the summation of the products across beliefs used to measure attitudes, subjective norms and PBC, and therefore to predict intention, hinder the possibility to recognize the beliefs or evaluations to concentrate on in interventions. The present study has utilised stepwise hierarchical regression analyses in order to establish if it is the belief, the assessment or the interaction term that is influential and be able to design boycott participation intention counter-measures based on an adequate understanding of the mechanisms by which boycott intention can be influenced.

In sum, the aim of this study is two-fold:

(a) To test the expectancy-value theory underpinning the beliefs behind boycott intentions in the Theory of Planned Behaviour, and

(b) To identify the specific beliefs that could be used as targets in counter-boycott interventions.

\section{Method}

The study was based on a comprehensive quantitative stage designed to test the expectancy theory underpinning the TPB framework applied to the specific field of consumer boycotting behaviour.

\subsection{Sample and Research Design}

The Lebanese context was an ideal test bed for this study because of the present accentuated feeling concerning the boycott and the diversity of the population which is highly representative of the Middle East as a whole. A multistage sampling technique was utilised. The country was stratified along the five local conglomerates: Southern Lebanon, Beqaa, Greater Beirut, Mount-Lebanon and Northern Lebanon. A systematic sampling method based on the fixed-lines telephone directory was used to compile contact numbers. The number of lines in each conglomerate was computed in proportion to the corresponding number of residents, with one respondent sampled from each household based on the 16 years and above age criteria. A sample of 500 Lebanese consumers completed the questionnaire designed to measure TPB variables with respect to the intention of participating in the boycott of American products in sign of protest against the US policy in the Middle East. The sample included $51.6 \%$ of males. Forty six percent of respondents were Muslims, the remainder were Christians. The author believes that the use of a randomized sample allows reaching a more accurate representation of the population than students' samples, as it is likely that students may be more prone to participate in boycott campaigns than others.

\subsection{Questionnaire Measures}

The measures adopted in the survey instrument were extracted not only from extant literature on boycott motivations as introduced in the literature, but also from the initial interview stage, which allowed to uncover specific measures related to the contact of the boycott under study. The results of the qualitative stage were particularly significant in the extraction of the normative beliefs components (i.e., family, close friends, colleagues, religious leader of one's community and most of the members of one's community) as these are very context-specific. 


\subsubsection{Behavioural Beliefs}

Participants were asked to evaluate on a 7-point semantic differential scale (1 to 7) how likely or unlikely they thought various outcomes would be if they participated in the boycott. The fourteen modal behavioural beliefs compiled at the exploratory stage (see appendix) were included in the questionnaire to obtain an indirect measure of attitude. Outcome evaluations were then measured by asking respondents to assess on a 7-point semantic differential scale $(-3$ to +3$)$ how good or bad those various results would be.

\subsubsection{Normative Beliefs}

Participants were asked to evaluate on a strongly disagree-strongly agree scale how much the five salient referents identified at the interview stage, namely: family, close friends, colleagues/co-workers, members of the community to which one belongs, and the religious leader of this community, would want them to boycott. Motivation to comply was then gauged by asking participants to rate on 7-points scales how much they would act upon the opinions of those referents.

\subsubsection{Control Beliefs}

Three control beliefs were used to evaluate participants' perception of the existence of variables that may potentially facilitate or deter respondents' boycott participation. To measure control-belief strength, respondents were asked to rate on 7-point (strongly disagree-strongly agree) scales their preference and dependence on the boycotted products, and how likely it is for them to find alternative viable substitutes for the boycotted products at a reasonable or competitive price. Three corresponding questions were similarly designed to assess the perceived power of the latter factors.

\subsubsection{Attitude}

A direct measure of attitude toward boycotting was computed through the averaging of the answers of each respondent on six items. The scale was borrowed from that the work of Ajzen and Driver (1992). Based on a semantic differential scale, respondents completed the following sentence: "my participation in the boycott against American companies would be/is..." by rating it on 7-point scales through six couples of adjectives. The assessment is based on three bipolar adjectives reflecting an instrumental dimension: "useless-useful, not beneficial-beneficial, and unfair-fair", and three reflecting a moral dimension with "bad-good, unreasonable-reasonable, and undesirable-desirable." Cronbach's $\alpha$ was .93.

\subsubsection{Subjective Norm}

Participants were asked to indicate their level of agreement with the following two items in order to assess subjective norm: "most people who are important to me think that I should boycott American companies" and "most people who are important to me, did/do actually participate in the boycott". Responses were scored on a 1 (strongly disagree) to 7 (strongly agree) scale, and a single measure was obtained by averaging the responses on the two scales. While the first scale has an injunctive quality, which often causes responses to have low variability because important others are generally perceived to approve of desirable behaviours and disapprove of undesirable ones, the second captures descriptive social norms, i.e. whether important others do themselves perform the behaviour. Cronbach's $\alpha$ for these two items was 92 .

\subsubsection{Perceived Behavioural Control}

The direct measure of PBC was obtained by asking participants to rate their capacity to refrain from buying the products and the likelihood of their having absolute control over the decision, by agreeing or disagreeing with two statements: "If I want I can refrain from buying American products" and "I have total control over whether I do or do not boycott American products." PBC was computed by averaging responses on these two items. The Cronbach's alpha statistic for internal consistence was .74.

\subsubsection{Intention}

Two 7-points (strongly disagree-strongly agree) semantic-differential items were designed to elicit respondents' intentions to boycott or continue boycotting: "I intend to start/keep on boycotting American products" and "I will try to start/keep on boycotting American products". Behavioural intention was computed by averaging responses on these two items. The intention inter-item correlation was .90 .

\section{Results}

\subsection{Analyses}

In line with previous similar studies (e.g., Elliott, Armitage, \& Baughan, 2005; Evans, 1991), stepwise hierarchical regression analyses were conducted for each of the TPB belief-based components. For each type of belief, two 
regression rounds were performed. The first was related to the forecast of the suitable direct TPB measure, and the second to the forecast of intention.

Also, for each of the three main measures, the individual belief components (i.e. outcome beliefs and outcome evaluation, normative beliefs and their corresponding motivation to comply, control beliefs and the related control beliefs perceived power) were entered consecutively in stages 1 and 2 , followed by their product terms in stage 3 . The increase in explained variance in the direct measure of the TPB or intention observed from stage 2 to stage 3 were examined to establish whether the multiplicative terms significantly contributed to the explained variance of the belief-based components and uniquely ascribed to the expectancy-value interaction (e.g., Armitage, Conner, Loach, \& Willetts, 1999; Trafimow \& Finlay, 2002). The standardised beta weights allowed identifying the most suitable beliefs to target in business counter-boycott interventions.

Before the product terms were computed, the individual belief variables were all mean-centred in order to reduce possible effects of multi-collinearity. In line with the evidence of multi-collinearity described by Elliott, Armitage and Baughan (2005), some individual components of beliefs, such as the fifth normative belief $\left(\mathrm{NORM}_{5}\right)$ stating, "the religious leader of this community thinks that I should boycott American companies as a sign of protest against the US policy in the Middle East" and its associated product term, showed significant standardised beta weights $\left(\beta_{\text {NORM } 5}=-.734 ; p<.001\right.$ in the prediction of the direct measure of subjective norm), while their related correlation coefficients were not statistically significant $\left(\mathrm{r}_{\mathrm{NORM}}=-.029\right)$.

Simplified regression models were formed by methodically eliminating items that were not statistically significant predictors of the direct TPB variables. For behavioural beliefs, if an outcome belief, its corresponding evaluation, and the corresponding product term were each not statistically significant predictors, then all were removed. Nevertheless, if the outcome belief, the corresponding outcome evaluation or the product term had a statistically significant beta weight, then all were retained. A similar method was adopted for normative and control beliefs.

In all, ten of the fourteen outcome beliefs and their matching outcome evaluations and product terms, two of the five normative beliefs, and two of the three control beliefs were retained in the analyses conducted for the direct measures of the TPB. Moreover, eight outcome beliefs, three normative beliefs, and all three control beliefs were retained in the analyses for intention prediction.

\subsection{The Expectancy-Value Concept Underpinning the TPB}

The objective of the study to test the expectancy-value concept was addressed by examining the increases to explained variance in the dependent variables (Tables 1-6). If the expectancy-value concept at the basis of the TPB is valid, the belief-based measure of attitude should theoretically correlate well with its corresponding direct measure (Hewstone \& Young, 1988). This assumption is supposed to hold true both for the measure of subjective norm and for the measure of PBC.

\subsubsection{Behavioural Beliefs}

Ten of the fourteen outcome beliefs remained in the analyses with their matching evaluations and multiplication terms, based on the statistical significance criteria (Table 1), Outcome beliefs explicated $72.4 \%$ of the explained variance in attitude $\left(\mathrm{R}^{2}=.724, p<.001\right)$. The adding of the outcome evaluation items in the second stage resulted in a statistically significant increase in $\mathrm{R}^{2}$ in the prediction of attitude $\left(\mathrm{R}^{2}=.786, \mathrm{R}_{\text {change }}^{2}=.062, p<.001\right)$. The related interaction terms added in the third stage, also led to statistically significant increases to the explained variance in attitudes $\left(\mathrm{R}^{2}=.817, \mathrm{R}_{\text {change }}^{2}=.031, p<.001\right)$. 
Table 1. Behavioural belief predictors of attitude

\begin{tabular}{|c|c|c|c|c|c|c|c|}
\hline \multirow{2}{*}{$\begin{array}{l}\text { Variables } \\
\text { Stage 1: Outcome Beliefs (OLIKs) }\end{array}$} & \multicolumn{2}{|c|}{ Mean $(\mathrm{SD})^{\mathrm{a}}$} & \multicolumn{2}{|c|}{$R^{2} \quad R_{\text {change }}^{2} F_{\text {change }}$} & \multicolumn{3}{|c|}{ Final $\beta \beta$ Sig. $\mathrm{R}$} \\
\hline & & & .724 .724 & $79.146^{* * *}$ & & & \\
\hline olik2 & 4.68 & 1.756 & & & .142 & .064 & $.731^{* * *}$ \\
\hline olik3 & 4.77 & 2.027 & & & -.116 & .117 & $.707^{* * *}$ \\
\hline olik4 & 4.80 & 2.267 & & & $.372^{* * *}$ & .000 & $.776^{* * *}$ \\
\hline olik5 & 4.46 & 1.837 & & & $-.458^{* * *}$ & $* .000$ & $.589^{* * *}$ \\
\hline olik6 & 4.58 & 1.865 & & & .085 & .227 & $.652^{* * *}$ \\
\hline olik8 & 3.57 & 2.199 & & & $.116^{*}$ & .037 & $.484^{* * *}$ \\
\hline olik9 & 4.62 & 1.866 & & & $.450^{* * *}$ & .000 & $.678^{* * *}$ \\
\hline olik11 & 4.60 & 1.913 & & & $-.347^{* * *}$ & $* .000$ & $.664^{* * *}$ \\
\hline olik12 & 4.95 & 1.942 & & & .036 & .641 & $.731^{* * *}$ \\
\hline olik14 & 5.16 & 1.792 & & & $.315^{* * *}$ & .001 & $.705^{* * *}$ \\
\hline Stage 2: Outcome Evaluations (OEVs) & & & .786 .062 & $8.526^{* * *}$ & & & \\
\hline oev2 & .83 & 1.805 & & & -.123 & .477 & $.632^{* * *}$ \\
\hline oev3 & .86 & 1.900 & & & $-.724^{* * *}$ & $* .000$ & $.617^{* * *}$ \\
\hline oev4 & .93 & 2.072 & & & .264 & .088 & $.734^{* * *}$ \\
\hline oev5 & .69 & 1.764 & & & $-.513^{* * *}$ & $* .001$ & $.486^{* * *}$ \\
\hline oev6 & .75 & 1.856 & & & .036 & .841 & $.581^{* * *}$ \\
\hline oev8 & .11 & 1.905 & & & .022 & .790 & $.372^{* * *}$ \\
\hline oev9 & .71 & 1.775 & & & .350 & .206 & $.612^{* * *}$ \\
\hline oev11 & .71 & 1.784 & & & $-.731^{* * *}$ & $* .000$ & $.570^{* * *}$ \\
\hline oev12 & 1.03 & 1.925 & & & $.524^{* * *}$ & .001 & $.749^{* * *}$ \\
\hline oev14 & 1.26 & 1.476 & & & $.680^{* * *}$ & .000 & $.661^{* * *}$ \\
\hline Stage 3 (Interaction Terms) & & & .817 .031 & $4.747^{* * *}$ & & & \\
\hline olik2_oev2 & 6.41 & 8.859 & & & .146 & .464 & $.692^{* * *}$ \\
\hline olik3_oev3 & 7.46 & 9.301 & & & $.705^{* *}$ & .002 & $.675^{* * *}$ \\
\hline olik4_oev4 & 8.70 & 10.604 & & & -.165 & .340 & $.747^{* * *}$ \\
\hline olik5_oev5 & 5.87 & 8.270 & & & $.720^{* * *}$ & .000 & $.549^{* * *}$ \\
\hline olik6_oev6 & 6.46 & 8.640 & & & -.118 & .559 & $.629^{* * *}$ \\
\hline olik8_oev8 & 3.78 & 8.313 & & & -.066 & .472 & $.402^{* * *}$ \\
\hline olik9_oev9 & 6.19 & 8.366 & & & -.333 & .310 & $.666^{* * *}$ \\
\hline olik11_oev11 & 6.29 & 8.326 & & & $.670^{* *}$ & .003 & $.641^{* * *}$ \\
\hline olik12_oev12 & 8.39 & 10.024 & & & -.245 & .161 & $.759^{* * *}$ \\
\hline olik14_oev14 & 8.56 & 8.688 & & & $-.750^{* * *}$ & $* .000$ & $.691^{* * *}$ \\
\hline
\end{tabular}

Note. ${ }^{*} p<.05 ; * * p<.01, * * * p<.001$.

In the testing of the expectancy-value underpinnings of behavioural beliefs as predictors of intention (Table 2), eight of the fourteen outcome beliefs were retained with matching evaluations and multiplication terms. Outcome beliefs explained $76.8 \%$ of the variance in intentions $\left(\mathrm{R}^{2}=.768, p<.001\right)$. The adding of the outcome evaluation items resulted in a statistically significant rise in $\mathrm{R}^{2}\left(\mathrm{R}^{2}=.833, \mathrm{R}_{\text {change }}^{2}=.065, p<.001\right)$. The adding of the interaction terms in the last stage also led to rises to explained variance in intentions $\left(\mathrm{R}^{2}=.847, \mathrm{R}^{2}\right.$ change $=.014, p$ 
$<.001$ ), substantiating once again the expectancy-value theory.

Table 2. Behavioural belief predictors of intentions

\begin{tabular}{|c|c|c|c|c|c|c|c|c|}
\hline Variables & Mean & $(\mathrm{SD})^{\mathrm{a}}$ & $\mathrm{R}^{2}$ & $\mathrm{R}_{\text {change }}^{2}$ & $\mathrm{~F}_{\text {change }}$ & Final $\beta$ & $\beta$ Sig. & $\mathrm{R}$ \\
\hline Stage 1: Outcome Beliefs (OLIKs) & & & .768 & .768 & $125.531^{* * *}$ & & & \\
\hline olik1 & 4.20 & 1.658 & & & & $-.283^{* * *}$ & .000 & $.682^{* * *}$ \\
\hline olik2 & 4.68 & 1.756 & & & & $.258^{* * *}$ & .001 & $.770^{* * *}$ \\
\hline olik4 & 4.80 & 2.267 & & & & $.122^{*}$ & .015 & $.769^{* * *}$ \\
\hline olik7 & 3.40 & 1.677 & & & & $.166^{* * *}$ & .001 & $.630^{* * *}$ \\
\hline olik9 & 4.62 & 1.866 & & & & $.426^{* * *}$ & .000 & $.746^{* * *}$ \\
\hline olik10 & 3.07 & 1.188 & & & & -.057 & .073 & $.142^{* *}$ \\
\hline olik12 & 4.95 & 1.942 & & & & -.092 & .164 & $.756^{* * *}$ \\
\hline olik13 & 5.68 & 1.065 & & & & $-.089^{* *}$ & .003 & $-.270^{* * *}$ \\
\hline Stage 2: Outcome Evaluations (OEVs) & & & .833 & .065 & $14.365^{* * *}$ & & & \\
\hline oev1 & .48 & 1.644 & & & & $-.358^{* *}$ & .002 & $.515^{* * *}$ \\
\hline oev2 & .83 & 1.805 & & & & .170 & .289 & $.686^{* * *}$ \\
\hline oev4 & .93 & 2.072 & & & & $-.413^{* * *}$ & .001 & $.767^{* * *}$ \\
\hline oev7 & .11 & 1.681 & & & & .078 & .371 & $.398^{* * *}$ \\
\hline oev9 & .71 & 1.775 & & & & $.604^{* *}$ & .004 & $.688^{* * *}$ \\
\hline oev10 & -.98 & 1.081 & & & & .122 & .066 & $-.175^{* * *}$ \\
\hline oev12 & 1.03 & 1.925 & & & & $.293^{*}$ & .025 & $.801^{* * *}$ \\
\hline oev13 & -1.28 & 1.359 & & & & -.011 & .931 & $.097^{*}$ \\
\hline Stage 3: (Interaction Terms) & & & .847 & .014 & $3.800^{* * *}$ & & & \\
\hline olik1_oev1 & 4.16 & 6.961 & & & & $.483^{* * *}$ & .000 & $.605^{* * *}$ \\
\hline olik2_oev2 & 6.41 & 8.859 & & & & -.085 & .653 & $.758^{* * *}$ \\
\hline olik4_oev4 & 8.70 & 10.604 & & & & $.496^{* * *}$ & .000 & $.800^{* * *}$ \\
\hline olik7_oev7 & 2.35 & 5.344 & & & & -.139 & .119 & $.486^{* * *}$ \\
\hline olik9_oev9 & 6.19 & 8.366 & & & & $-.625^{* *}$ & .010 & $.745^{* * *}$ \\
\hline olik10_oev10 & -2.56 & 3.132 & & & & $-.137^{*}$ & .035 & $-.285^{* * *}$ \\
\hline olik12_oev12 & 8.39 & 10.024 & & & & -.036 & .805 & $.815^{* * *}$ \\
\hline olik13_oev13 & -7.83 & 8.594 & & & & .066 & .624 & $.134^{* *}$ \\
\hline
\end{tabular}

Note. ${ }^{*} p<.05 ; * * p<.01, * * * p<.001$.

\subsubsection{Normative Beliefs}

In the analysis of normative belief predictors of $\mathrm{SN}$, two out of the five outcome beliefs were retained in the analysis with their matching outcome evaluations and multiplication terms, namely those related to whether most members of one's family $\left(\mathrm{NORM}_{1}\right)$ and the members of the community to which one belongs $\left(\mathrm{NORM}_{4}\right)$ think that the participant should boycott American companies. These normative beliefs explained $31.9 \%$ of the variance in $\mathrm{SN}\left(\mathrm{R}^{2}=.319, p<.001\right)$. When added, the MTC items did not significantly augment the percentage of variance in $\mathrm{SN}\left(\mathrm{R}^{2}=.325, \mathrm{R}_{\text {change }}^{2}=.006\right.$, not significant). Nevertheless, the related multiplication terms led to a significant rise in $\mathrm{R}^{2}$ for $\mathrm{SN}\left(\mathrm{R}^{2}=.354, \mathrm{R}_{\text {change }}^{2}=.029, p<.001\right)$, hence corroborating the expectancy-value model. 
Table 3. Normative belief predictors of SN

\begin{tabular}{|c|c|c|c|c|c|c|c|c|}
\hline Variables & Mean & $(\mathrm{SD})^{\mathrm{a}}$ & $\mathrm{R}^{2}$ & $\mathrm{R}_{\text {change }}^{2}$ & $F_{\text {change }}$ & Final $\beta$ & $\beta$ Sig. & $\mathrm{R}$ \\
\hline Stage 1: Normative Beliefs (NORMs) & & & .319 & .319 & $55.144^{* * *}$ & & & \\
\hline NORM1 & -.29 & 1.794 & & & & .003 & .986 & $.406^{* * *}$ \\
\hline NORM4 & -.36 & 1.676 & & & & $.822^{* * *}$ & .000 & $.438^{* * *}$ \\
\hline Stage 2: Motivation to Comply (MTCs) & & & .325 & .006 & 0.967 & & & \\
\hline MTC1 & 4.60 & 1.439 & & & & -.106 & .148 & -.071 \\
\hline MTC4 & 4.38 & 1.354 & & & & $.187^{*}$ & .019 & $.302^{* * *}$ \\
\hline Stage 3: (Interaction Terms) & & & .354 & .029 & $5.213^{* *}$ & & & \\
\hline NORM1*MTC1 & -.33 & 8.550 & & & & $.414^{*}$ & .042 & $.431^{* * *}$ \\
\hline NORM4*MTC4 & -.58 & 7.732 & & & & $-.537^{*}$ & .030 & $.436^{* * *}$ \\
\hline
\end{tabular}

Note. ${ }^{*} p<.05 ; * * p<.01, * * * p<.001$.

For the prediction of intention, the item related to the religious leader of this community $\left(\mathrm{NORM}_{5}\right)$ was retained as a significant predictor in addition to the two items that were significantly predictive of SN. These referent beliefs explain $36.9 \%$ of the variance in intentions $\left(\mathrm{R}^{2}=.369, p<.001\right)$. Nevertheless, in contrast with the analysis linked to $\mathrm{SN}$, the addition of the MTC items in the second stage significantly increased the fraction of variance explained for intention $\left(\mathrm{R}^{2}=.400, \mathrm{R}_{\text {change }}^{2}=.031, p<.001\right)$. Moreover, the product terms added in the last stage led to a significant augmentation to $\mathrm{R}^{2}$ in the measurement of intention $\left(\mathrm{R}^{2}=.434, \mathrm{R}_{\text {change }}^{2}=.034, p<.001\right)$.

Table 4. Normative belief predictors of intention

\begin{tabular}{|c|c|c|c|c|c|c|c|}
\hline Variables & Mear & $(\mathrm{SD})^{\mathrm{a}}$ & $\mathrm{R}^{2} \quad \mathrm{R}_{\text {chang }}^{2}$ & ${ }_{e} F_{\text {change }}$ & Final $\beta$ & $\beta$ Sig & \\
\hline Stage 1: Normative Beliefs (NORMs) & & & .369 .369 & $45.577^{* * *}$ & & & \\
\hline NORM1 & -.29 & 1.794 & & & .027 & .884 & $.406^{* * *}$ \\
\hline NORM4 & -.36 & 1.676 & & & $.772^{* * *}$ & .001 & $.438^{* * *}$ \\
\hline NORM5 & -.49 & 2.337 & & & $-.734^{* * *}$ & .000 & -.029 \\
\hline Stage 2: Motivation to Comply (MTCs) & & & .400 .031 & $3.985^{* *}$ & & & \\
\hline MTC1 & 4.60 & 1.439 & & & -.120 & .087 & .071 \\
\hline MTC4 & 4.38 & 1.354 & & & $.174^{*}$ & .028 & $.302^{* * *}$ \\
\hline MTC5 & 4.43 & 1.756 & & & $.168^{*}$ & .021 & $.327^{* * *}$ \\
\hline Stage 3: (Interaction Terms) & & & .434 .034 & $4.550^{* *}$ & & & \\
\hline NORM1*MTC1 & -.33 & 8.550 & & & .328 & .092 & $.431^{* * *}$ \\
\hline NORM4*MTC4 & -.58 & 7.732 & & & $-.466^{*}$ & .049 & $.436^{* * *}$ \\
\hline NORM5*MTC5 & -.16 & 11.903 & & & $.480^{*}$ & .021 & .054 \\
\hline
\end{tabular}

Note. ${ }^{*} p<.05 ; * p<.01, * * * p<.001$.

\subsubsection{Control Beliefs}

In the analysis of control belief predictors of PBC, two of the three outcome beliefs were retained with their matching evaluations and multiplication terms. These were related to the following beliefs: "I generally prefer American products to all other products," $\left(\mathrm{CBS}_{1}\right)$ and "I depend heavily on American products" $\left(\mathrm{CBS}_{2}\right)$. As reflected in Table 5, control frequency beliefs explained $52.2 \%$ of the variance in $\mathrm{PBC}\left(\mathrm{R}^{2}=.522, p<.001\right)$. The addition of CBPP in the second stage led to a non- statistically significant increase to explained variance in PBC $\left(\mathrm{R}^{2}=.528, \mathrm{R}_{\text {change }}^{2}=.006\right.$, not significant). The adding of the multiplication terms also resulted in a non-statistically significant increase in explained variance in $\operatorname{PBC}\left(\mathrm{R}^{2}=.537, \mathrm{R}_{\text {change }}^{2}=.009\right.$, not significant), and therefore did not provide evidence for the model for control beliefs related to PBC. 
Table 5. Control belief predictors of PBC

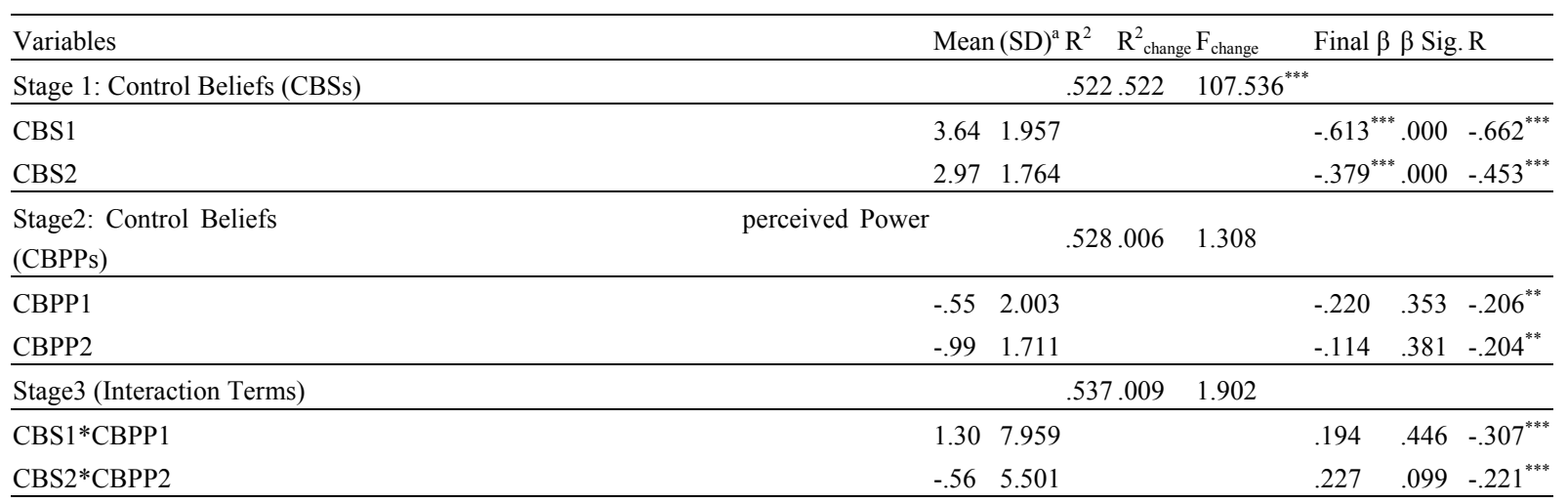

Note. ${ }^{*} p<.05 ; * * p<.01, * * * p<.001$.

Conversely, all beliefs, including: "I cannot find substitutes to most American products at reasonable or competitive prices" $\left(\mathrm{CBS}_{3}\right)$ were kept as significant predictors of intentions. In fact, control frequency belief items (Table 6 ) accounted for $25.8 \%$ of the variance in intentions $\left(\mathrm{R}^{2}=.258, p<.001\right)$. The adding of CBPP led to a non-statistically significant increment to explained variance in intention $\left(\mathrm{R}^{2}=.278, \mathrm{R}_{\text {change }}^{2}=.020\right.$, not significant) Nonetheless, the interaction terms added in the last stage resulted in a statistically significant increase to the explained variance in intention $\left(\mathrm{R}^{2}=.333, \mathrm{R}_{\text {change }}^{2}=.054, p<.001\right)$, verifying once more the expectancy-value model.

Table 6. Control belief predictors of intention

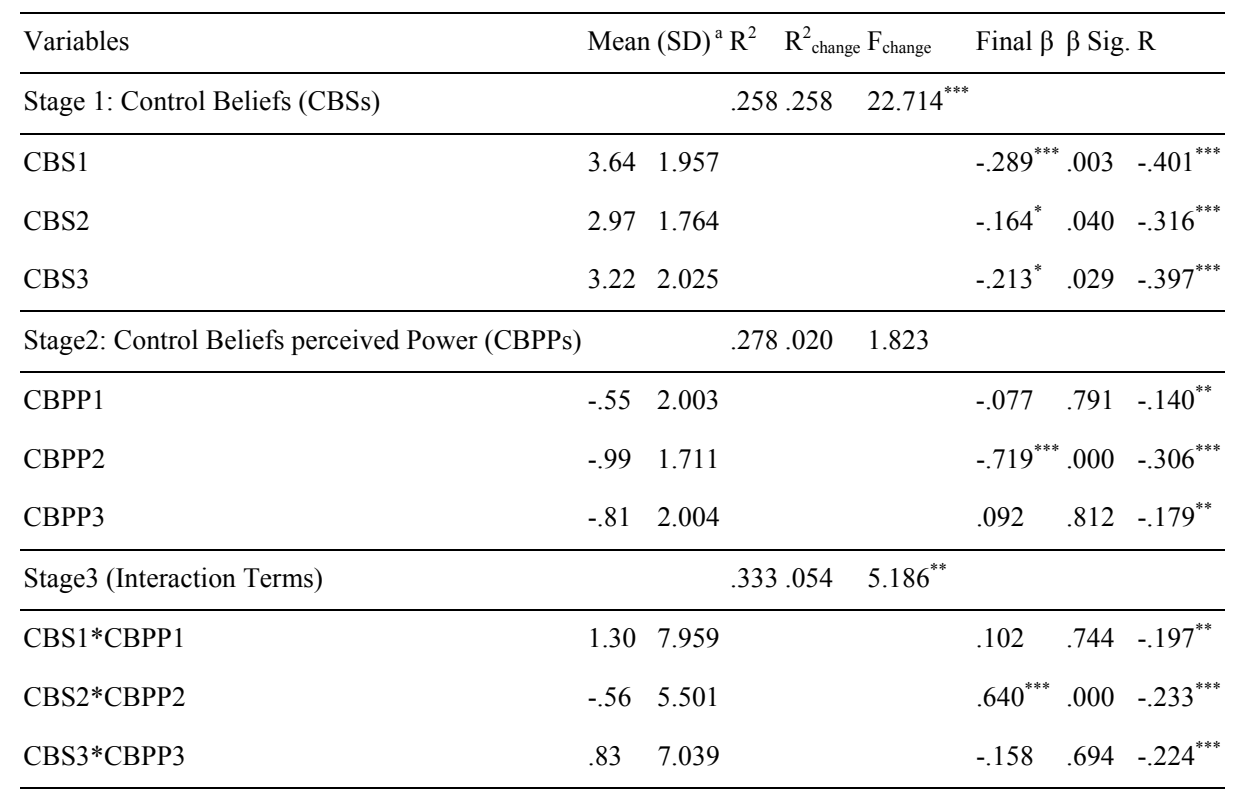

Note. ${ }^{*} p<.05 ; * * p<.01, * * * p<.001$.

\subsection{Identifying Belief Targets for Counter-Boycott Participation Interventions}

In line with Fishbein and Ajzen's (1991) argument that altering significant beliefs would lead to equivalent modifications in attitudes, SN, PBC, and intentions, the second objective of this study was to recognize the beliefs that could be used in designing interventions to change consumers' intention to participate in the boycott. For this purpose, the final standardised beta weights of the predictors of the direct TPB measures and intention were examined, as changes in these beliefs, particularly those directly predicting intentions, can lead to parallel changes in their direct counterpart, and consequently on intentions. 


\subsubsection{Behavioural Targets}

\section{- Predictors of Attitude}

Ten outcome beliefs, namely $\mathrm{OLIK}_{2}, \mathrm{OLIK}_{3}, \mathrm{OLIK}_{4}, \mathrm{OLIK}_{5}, \mathrm{OLIK}_{6}, \mathrm{OLIK}_{8}, \mathrm{OLIK}_{9}, \mathrm{OLIK}_{11}, \mathrm{OLIK}_{12}, \mathrm{OLIK}_{14}$, predicted attitude (Table 1 ). The only six outcome beliefs that were the statistically significant independent predictors of attitude were the supposed possibility that participating in the boycott would "help me act according to my personal values" $\left(\mathrm{OLIK}_{4}, p<.001\right)$, "allow me to help the people affected negatively by the US policy in the Middle East" $\left(\mathrm{OLIK}_{5}, p<.001\right)$, "help me express my religious beliefs" $\left(\mathrm{OLIK}_{8}, p<.05\right)$, "help me satisfy my sense of responsibility towards the Arab community" $\left(\mathrm{OLIK}_{9}, p<.001\right)$, "help me express my Arab identity" (OLIK ${ }_{11}, p$ $<.001)$, "make me feel that I am a winner when I participate in a successful boycott" $\left(\mathrm{OLIK}_{14}, p<.001\right)$.

The five evaluations of the outcomes that participating in the boycott would "help me release my anger in a peaceful way toward the US policy in the Middle East" $\left(\mathrm{OEV}_{3}, p<.001\right)$, "help the people affected negatively by the US policy in the Middle East" $\left(\mathrm{OEV}_{5}, p<.001\right)$, "help me express my Arab identity" $\left(\mathrm{OEV}_{11}, p<.001\right)$, "help the campaign to achieve its objectives" $\left(\mathrm{OEV}_{12}, p<.001\right)$, "make me feel I am a winner when I participate in a successful boycott" $\left(\mathrm{OEV}_{14}, p<.001\right)$ were significant independent predictors of attitude.

The interaction terms for "participating in the boycott would help me release my anger in a peaceful way" (OLIK - $\left.\mathrm{OEV}_{3}, p<.001\right)$, "I feel I am a winner when I participate in a successful boycott" $\left(\mathrm{OLIK}_{5}-\mathrm{OEV}_{5}, p<.01\right)$, "participating in the boycott would help me express my Arab identity" $\left(\mathrm{OLIK}_{11}-\mathrm{OEV}_{11}, p<.01\right)$, and "participating in the boycott would allow me to help the people affected negatively by the US policy in the Middle East" $\left(\mathrm{OLIK}_{14}-\mathrm{OEV}_{14}, p<.001\right)$ were statistically significant predictors of attitude.

- Predictors of Intentions

Table 2 shows that eight outcome beliefs predicted intentions, namely the following: $\mathrm{OLIK}_{1}, \mathrm{OLIK}_{2}, \mathrm{OLIK}_{4}$, $\mathrm{OLIK}_{7}, \mathrm{OLIK}_{9}, \mathrm{OLIK}_{10}, \mathrm{OLIK}_{12}$, and $\mathrm{OLIK}_{13}$. The only six outcome beliefs that were the statistically significant independent predictors of intentions were related to the supposed possibility that participating in the boycott would "have an impact on the operations of the boycotted companies" $\left(\mathrm{OLIK}_{1}, p<.001\right)$, "raise the effectiveness of the campaign by encouraging people around me to boycott" $\left(\mathrm{OLIK}_{2}, p<.001\right)$, "help me act according to my personal values" $\left(\mathrm{OLIK}_{4}, p<.05\right)$, "have an impact on the US government stance" $\left(\mathrm{OLIK}_{7}, p<.001\right)$, "help me satisfy my sense of responsibility towards the Arab community" $\left(\mathrm{OLIK}_{9}, p<.001\right)$, "put many local workers' jobs in danger" $\left(\mathrm{OLIK}_{13}, p<.01\right)$.

The four evaluations of the outcomes that boycott participation would "have an impact on the operations of the boycotted companies" $\left(\mathrm{OEV}_{1}, p<.01\right)$, "help me act according to my personal values" $\left(\mathrm{OEV}_{4}, p<.001\right)$, "help me satisfy my sense of responsibility towards the Arab community" $\left(\mathrm{OEV}_{9}, p<.01\right)$, "help the campaign to achieve its objectives" $\left(\mathrm{OEV}_{12}, p<.05\right)$, were significant independent predictors of intentions.

The four interaction terms for "my participation in the boycott would have an impact on the operations of the boycotted companies" $\left(\mathrm{OLIK}_{1}-\mathrm{OEV}_{1}, p<.001\right)$, "participating in the boycott would help me act according to my personal values" $\left(\mathrm{OLIK}_{4}-\mathrm{OEV}_{4}, p<.001\right)$, "participating in the boycott would help me satisfy my sense of responsibility towards the Arab community" (OLIK $\left.9-\mathrm{OEV}_{9}, p<.01\right)$, and "I could enjoy the final outcomes of the boycott without personally participating in it" $\left(\mathrm{OLIK}_{10}-\mathrm{OEV}_{10}, p<.05\right)$ were statistically significant predictors of intentions.

\subsubsection{Normative Targets}

As can be seen from tables 3 and 4, each of the two referent beliefs related to one's family and the members of one's community were positively related predictors of both SN and intention. "My family thinks that I should boycott American products" $\left(\mathrm{NORM}_{1}\right)$ was not significant in the prediction of either subjective norm or intention. The item "most of the members of my community think that I should boycott American products" $\left(\mathrm{NORM}_{4}\right)$ was statistically significant in the prediction of both subjective norm and intention $(p<.001)$. The referent belief related to the item "the religious leader of my community thinks that I should boycott American products" was a statistically significant negatively associated predictor of intentions $\left(\mathrm{NORM}_{5}, p<.001\right)$, but not of subjective norms.

The MTC items associated with the referents mentioned above did not cause additional statistically significant variance to subjective norm besides the one accounted for by the referent beliefs, although one of the MTC items, namely "when it comes to purchasing choices, I generally want to do what most of the members of my community think I should do" $\left(\mathrm{MTC}_{4}, p<.05\right)$, was a statistically significant predictor of both subjective norm and intention. The MTC item related to "when it comes to purchasing choices, I generally want to do what the religious leader of my community think I should do" had a standardized positive and statistically significant final beta weight in the 
prediction of intention $\left(\mathrm{MTC}_{5}, \beta=-.168, p<.05\right)$.

The multiplication term related to one's family $\left(\mathrm{NORM}_{1}-\mathrm{MTC}_{1}\right)$ had a statistically significant negative standardised beta weight in the prediction of SN $(p<.05)$, but it did not have a significant beta weight in the prediction of intention. Moreover, the interaction term related to most members of one's community $\left(\mathrm{NORM}_{4}-\right.$ $\left.\mathrm{MTC}_{1}\right)$ had statistically significant negative standardised beta weights in the prediction of both SN and intention ( $p$ $<.05)$. Finally, the product term between the normative belief and the motivation to comply with the religious leader of one's community $\left(\mathrm{NORM}_{5}-\mathrm{MTC}_{5}\right)$ had a statistically significant standardised beta weight in the prediction of intention $(p<.05)$.

\subsubsection{Control Targets}

Tables 5 and 6 show that the control frequency beliefs corresponding to the following items "I generally prefer American products to all other products" $\left(\mathrm{CBS}_{1}, p<.001\right)$ and "I depend heavily on American products" $\left(\mathrm{CBS}_{2}, p\right.$ $<.001$ for the prediction of PBC, and $p<.05$ for intention) significantly predicted both the direct measure of PBC and intention. These two frequency beliefs that were common independent predictors of both, were negatively related to both $\mathrm{PBC}$ and intention. The frequency belief regarding "I cannot find substitutes to most American products at reasonable or competitive prices" was a statistically significant, negatively related, predictor of $\mathrm{PBC}$ only $\left(\mathrm{CBS}_{3}, p<.05\right)$.

The control beliefs perceived power related to the following two items: "my preference for American products prevents me from participating in the boycott" $\left(\mathrm{CBPP}_{1}\right)$, and "my dependence on American products prevents me from participating in the boycott" $\left(\mathrm{CBPP}_{2}\right)$ were negatively related both to $\mathrm{PBC}$ and to that of intention. The first control belief perceived power item was not statistically significant either to $\mathrm{PBC}$ or intention, whereas the second one was a statistically significant predictor only to intention $\left(\mathrm{CBPP}_{2}, p<.001\right)$. The third control beliefs perceived power predictor of intention only, namely related to the item "the unavailability of substitutes to most of the American products at a reasonable price enables me to participate in the boycott" showed to be statistically insignificant to the latter prediction.

While none of the interaction terms were statistically significant in the prediction of $\mathrm{PBC}$, only the product term related to one's dependence on American products $\left(\mathrm{CBS}_{2}-\mathrm{CBPP}_{2}\right)$ significantly predicted intention $(p<.001)$.

The results presented provided support for the expectancy-value model. Explicit belief predictors of consumers' attitudes, SN, PBC, and more importantly, intentions were acknowledged accordingly. Affecting these beliefs through specific interventions, especially those predictors of intention as they are considered as the direct proximal predictors of behaviour, may be particularly effective in altering consumers boycott intention

\section{Discussion}

The testing of the expectancy-value concept underpinning the TPB outcome beliefs and evaluations each made significant contributions to the prediction of the direct measure of attitude and intentions. Consistently with extant studies (Elliott et al., 2005; Rise, Ajstrom, \& Sutton, 1998; Sutton, McVey, \& Glanz, 1999), the behavioural beliefs multiplication terms contributed significantly to the explained variance in the related dependent variables. Yet, analyses revealed the existence of negative interactions. This can be due to the fact that the related outcomes were considered as highly likely (Elliott et al., 2005 and Shah \& Higgins, 1997). Since the negative interactions were statistically significant, the results showing that the multiplicative terms led to statistically significant rises to explained variances gave support to the expectancy-value model. Moreover, the fact that the MTC component did not separately add to SN implies that it is by itself not a central component underpinning consumers' boycott intention. Nonetheless, the results reflect that the importance of the motivation to comply construct resides in the interaction between referent beliefs and MTC, which justified significant variances in both SN and intentions. Furthermore, the analyses related to control belief predictors of $\mathrm{PBC}$ and intention reveal that in five out of the six instances, support for the expectancy-value model was provided. All in all, the results demonstrated that all belief multiplication terms led to statistically significant increases in explained variance beyond the individual indirect or belief-based items not only in the direct measures of the TPB model, but also in intention. Although increments typically ranged between $2 \%$ and $6 \%$, this does not refute their relevance. These increments are actually similar in magnitude to those cited in extant the literature (e.g., Elliott et al., 2005; Rise et al., 1998). Accordingly, this study provided evidence to support the use of the multiplicative assumption of belief-based attitude, subjective norm and PBC formation, hence confirming the underlying expectancy-value principle that underpins the TPB in the area of consumer boycott intention.

Understanding why consumers choose to participate in boycotts is an important issue both for social scientists and management who formulate related counter-behaviour strategy. Despite the importance of understanding the 
antecedents of boycotting behaviour, most of the related literature has lacked theoretical foundation. The present study has successfully applied the TPB to the study of boycott motives especially at a macro-level whereby countries are targeted. This study is of significance to business managers who need to develop appropriate strategic responses to counteract the negative effects of boycotts (Klein \& John, 2003). By understanding consumers' motivation, a targeted company can minimize the damage by identifying its' optimal strategic response. This may extend to the maintenance of its plans or policies unchanged by influencing the opinion and the decision-making process of the consumers by tackling the identified motivating beliefs. Targeting these beliefs in interventions may be effective in minimizing potential consequences both on the corporate image and financial performance level.

With regards to the development of suitable intervention, the researcher agrees with existing literature on attitude change that, in terms of intervention designs, the more intensive the counter-boycott message to which consumers are exposed, the more likely is the latter to have an effect on attitudes, intentions and behaviour. Moreover, the message persuasiveness is made all the more powerful as per Elliott, Armitage and Baughan's (2005) convincing contention, when: (a) the arguments presented appear credible, (b) the delivery of the arguments is made over a period of time rather than just once, and (c) the audience is enthusiastic to reflect on the matter tackled and the argument provided. This last aspect is expected to lead to a rather enduring change in attitude rather than just to a transitory and reactionary effect, in which case the normative influence is likely to bring back one's original behaviour.

\section{Conclusion}

This paper granted evidence to the validity of expectancy-value model, and helped delineate the specific belief predictors of consumers' attitudes, SN, PBC and intentions. Focusing on altering these beliefs to convince consumers not to boycott American products could be valuable in counteracting the studied behaviour. Nevertheless, additional research is necessary to discover useful ways to alter consumers' beliefs, attitudes, intentions and eventually their boycotting behaviour. Beliefs detected in this research can be utilised as a basis for this kind of studies. Research where interventions are directed in the context of boycotting specific products by consumers and assessed using a large sample sizes could be worthwhile.

Moreover, while this study has focused on consumer products, future research could tackle consumers boycotting behaviour towards services. Indeed looking at whether consumers react differently towards different offerings, i.e. products versus services, or even between different types of products should be insightful to businesses. Besides, including a component on the accurate knowledge of products' country-of-origin or the effects of hybrid products to research related to boycotting motivation is also an interesting future research venue. In fact, some recent research on hybrid or bi-national products, those that have been designed and manufactured in different countries (Chao, 1993; Verlegh \& Steenkamp, 1999) has indicated that these products seem to moderate consumer judgments and purchase intentions (Funk, Arthurs, Treviño, \& Joireman, 2010). Future studies could look at the latter impact on consumer boycott decisions.

\section{References}

Ajzen, I. (1991). The theory of planned behaviour. Organizational Behaviour and Human Decision Processes, 50, 179-211. http://dx.doi.org/10.1016/0749-5978(91)90020_T

Ajzen, I. (2001). Nature and operation of attitudes. Annual Review of Psychology, 52, 27-58. http://dx.doi.org/10.1146/annurev.psych.52.1.27

Ajzen, I., \& Driver, B. (1992). Application of the theory of planned behaviour to leisure choice. Journal of Leisure Research, 24(3), 207-224. http://dx.doi.org/10.1080/01490409109513137

Ajzen, I., \& Fishbein, M. (2000). Attitudes and the attitude-behaviour relation: Reasoned and automatic processes. European Review of Social Psychology, 11, 1-34. http://dx.doi.org/10.1080/14792779943000116

Al-Zobaidy, O. (2007). Boycott calls gathering momentum in Kingdom. Retrieved from $\mathrm{http}: / \mathrm{www}$.arabnews.com/?page=1\&section $=0 \&$ article $=17879 \& \mathrm{~d}=19 \& \mathrm{~m}=8 \& \mathrm{y}=2002$

Armitage, C., \& Christian, J. (2003). From attitudes to behaviour: Basic and applied research on the theory of planned behaviour. Current Psychology: Developmental, Learning, Personality, Social, 22(3), 187-195. http://dx.doi.org/10.1007/s12144-003-1015-5

Armitage, C., Conner, M., Loach, J., \& Willetts, D. (1999). Different perceptions of control: Applying an extended theory of planned behaviour to legal and illegal drug use. Basic and Applied Social Psychology, 21(4), 301-316. http://dx.doi.org/10.1207/s15324834basp2104_4 
Brewer, M., \& Brown, R. (1998). Inter-group relations. In D. T. Gilbert, S. T. Fiske \& G. Lindzey (Eds.), Handbook of social psychology. Boston: McGraw-Hill. http://dx.doi.org/10.1002/9780470561119

Borders, A., Earleywine, M., \& Huey, S. J. (2004). Predicting problem behaviours with multiple expectancies: Expanding expectancy-value theory. Adolescence, 39, 539-550. Retrieved from http://go.galegroup.com.proxy.lib.utk.edu

Cronbach, L. (1951). Coefficient alpha and the internal structure of tests. Psychometrika, 16, 297-334. http://dx.doi.org/10.1007/bf02310555

Chao, P. (1993). Partitioning Country of Origin Effects: Consumer Evaluations of a Hybrid Product. Journal of International Business Studies, 24(2), 291-306. http://dx.doi.org/10.1057/palgrave.jibs.8490851

Cohen, J. (1978). Partialed products are interactions; partialed powers are curve components. Psychological Bulletin, 85, 858-866. http://dx.doi.org/10.1037/0033-2909.85.4.858

Davidson, N., Worrell, D., \& El-Jelly, A. (1995). Influencing managers to change unpopular corporate behaviour through boycotts and divestitures. Business Sociology, 34, 171-196. http://dx.doi.org/10.1177/000765039503400204

Eagly, A., \& Chaiken, S. (1993). The psychology of attitudes. New York, NY: Harcourt Brace \& Company. http://dx.doi.org/10.1002/mar.4220120509

Elliott, M., Armitage, C., \& Baughan, C. (2003). Drivers' compliance with speed limits: An application of the theory of planned behaviour. Journal of Applied Psychology, 88, 964-972. http://dx.doi.org/10.1037/0021-9010.88.5.964

Elliott, M., Armitage, C., \& Baughan, C. (2005). Exploring the beliefs underpinning drivers' intentions to comply with speed limits. Transportation Research Part F: Traffic Psychology and Behaviour, 8(6), 459-479. http://dx.doi.org/10.1016/j.trf.2005.08.002

Evans, M. (1991). The problem of analyzing multiplicative composites: Interactions revisited. American Psychologist, 46, 6-15. http://dx.doi.org/10.1037//0003-066x.46.1.6

Field, A. (2005). Discovering statistics using SPSS (and sex, drugs and rock'n'roll) (2nd ed.). London: Sage Publications. http://dx.doi.org/10.5860/choice.43-3433

Fishbein, M., \& Ajzen, I. (1975). Belief, attitude, intention, and behaviour: An introduction to theory and research. Reading, MA: Addison-Wesley. http://dx.doi.org/10.2307/2065853

Friedman, M. (1999). Consumer boycotts: Effecting change through the marketplace and the media. New York: Routledge. http://dx.doi.org/10.5860/choice.38-0630

Funk, C. A., Arthurs, J. D., Treviño, L. J., \& Joireman, J. (2010). Consumer animosity in the global value chain: The effect of international production shifts on willingness to purchase hybrid products. Journal of International Business Studies, 41(4), 639-651. http://dx.doi.org/10.1057/jibs.2009.29

Hardin, G. (1968). The tragedy of the commons. Science, 162, 1243-1248. http://dx.doi.org/10.1126/science.162.3859.1243

Hewstone, M., \& Young, L. (1988). Expectancy-value models of attitude: Measurement and combination of evaluations and beliefs. Journal of Applied Social Psychology, 18, 958-971. http://dx.doi.org/10.1111/j.1559-1816.1988.tb01186.x

Klein, J., Ettenson, R., \& Morris, M. (1998). The animosity model of foreign product purchase: An empirical test in the people's republic of china. Journal of Marketing, 62, 89-100. http://dx.doi.org/10.2307/1251805

Klein, J., \& John, A. (2003). The boycott puzzle: Consumer motivations for purchase sacrifice. Management Science, 49(9), 1196-1209. http://dx.doi.org/10.1287/mnsc.49.9.1196.16569

Klein, J., Smith, N., \& John, A. (2002). Exploring motivations for participation in a consumer boycott. Advances in Consumer Research, 29(1), 363-369. http://dx.doi.org/10.1287/mnsc.49.9.1196.16569

Klein, J., Smith, N., \& John, A. (2004). Why we boycott: Consumer motivations for boycott participation. Journal of Marketing, 68(3), 92-109. http://dx.doi.org/10.1509/jmkg.68.3.92.34770

Kline, P. (1999). The handbook of psychological testing (2nd ed.). London: Routledge. http://dx.doi.org/10.4324/9781315812274

Lajunen, T. R. M. (2004). Can social psychological models be used to promote bicycle helmet use among 
teenagers? A comparison of the health belief model, theory of planned behaviour and the locus of control. Journal of Safety Research, 35(1), 115. http://dx.doi.org/10.1016/j.jsr.2003.09.020

Mazis, M. B., Ahtola, O. T., \& Klippel, R. E. (1975). A comparison of four multi-attribute models in the prediction of consumer attitudes. Journal of Consumer Research, 2, 38-52. http://dx.doi.org/10.1086/208614

Olson, M. (1965). The logic of collective action: Public goods and the theory of groups. Cambridge, MA: Harvard University Press. http://dx.doi.org/10.1007/978-3-531-90400-9_92

Pittman, T. (1998). Motivation. In Daniel T. Gilbert, S. T. Fiske \& G. Lindzey (Eds.), Handbook for social psychology. Boston: McGraw-Hill. http://dx.doi.org/10.1002/9780470561119

Pruitt, S., \& Friedman, M. (1986). Determining the effectiveness of consumer boycotts: A stock price analysis of their impact on corporate targets. Journal of Consumer Policy, 375-387. http://dx.doi.org/10.1007/BF00380573

Pruitt, S., White, R., \& Wei, J. (1988). The impact of union-sponsored boycotts on the stock prices of target firms. Journal of Labour Research, 9(3), 285-289. http://dx.doi.org/10.1007/bf02685318

Rise, J., Ajstrom, A., \& Sutton, S. (1998). Predicting intentions and use of dental floss among adolescents: An application of the theory of planned behaviour. Psychology and Health, 13, 223-236. http://dx.doi.org/10.1080/08870449808406748

Sen, S., Gurhan-Canli, Z., \& Morwitz, V. (2001). Withholding consumption: A social dilemma perspective on consumer boycotts. Journal of Consumer Research, 28(4), 399-417. http://dx.doi.org/10.1086/323729

Smith, C. (1990). Morality and the market: Consumer pressure for corporate accountability. London: Routledge. http://dx.doi.org/10.1016/0024-6301(90)90183-5

Smith, N., Klein, J., \& John, A. (2003). Consumer motivations for boycott participation: A field study. Paper presented at the European advances in consumer research, Dublin. http://dx.doi.org/10.1509/jmkg.68.3.92.34770

Sutton, S., McVey, D., \& Glanz, A. (1999). A comparative test of the theory of reasoned action and the theory of planned behaviour in the prediction of condom use intentions in a national sample of English young people. Health Psychology, 18, 72-81. http://dx.doi.org/10.1037//0278-6133.18.1.72

Tajfel, H. (1982). Social identity and inter-group relations. Cambridge, U.K.: Cambridge University Press.

Trafimow, D., \& Finlay, K. (2002). The prediction of attitudes from beliefs and evaluations: The logic of the double negative. British Journal of Social Psychology, 41, 77-86. http://dx.doi.org/10.1348/014466602165063

Tyler, T., \& McGraw, K. (1983). The threat of nuclear war: Risk interpretation and behavioural response. Journal of Social Issues, 39, 25-40. http://dx.doi.org/10.1111/j.1540-4560.1983.tb00128.x

Verlegh, P. W., \& Steenkamp, J. E. (1999). A review and meta-analysis of country-of-origin research. Journal of Economic Psychology, 20(5), 521-546. http://dx.doi.org/10.1016/s0167-4870(99)00023-9

\section{Appendix}

The beliefs included in the questionnaire and associated with the intention to participate in the boycott of American products, were as follows:

\section{1) Behavioural Beliefs:}

$\mathrm{BB}_{1}$ : has an impact on the operations of the boycotted companies.

$\mathrm{BB}_{2}$ : raises the effectiveness of the campaign by encouraging people around me to boycott.

$\mathrm{BB}_{3}$ : helps me release peacefully my anger toward the US policy in the Middle East.

$\mathrm{BB}_{4}$ : helps me act according to my personal values.

$\mathrm{BB}_{5}$ : allows me to help the people affected negatively by the US policy in the Middle East.

$\mathrm{BB}_{6}$ : helps me preserve my sense of belonging with my community, which was negatively affected by the US policy in the Middle East.

$\mathrm{BB}_{7}$ : has an impact on the US government stance.

$\mathrm{BB}_{8}$ : helps me express my religious beliefs. 
$\mathrm{BB}_{9}$ : helps me satisfy my sense of responsibility towards the Arab community.

$\mathrm{BB}_{10}$ : makes me enjoy the final outcomes of the boycott without personally participating in it.

$\mathrm{BB}_{11}$ : helps me express my Arab identity.

$\mathrm{BB}_{12}$ : helps the campaign to achieve its objectives.

$\mathrm{BB}_{13}$ : puts many local workers' jobs in danger.

$\mathrm{BB}_{14}$ : helps me feeling that I am a winner if the boycott is successful.

\section{2) Normative Beliefs:}

$\mathrm{NB}_{1}$ : My family

$\mathrm{NB}_{2}$ : My close friends

$\mathrm{NB}_{3}$ : My colleagues.

$\mathrm{NB}_{4}$ : Most of the members of my community.

$\mathrm{NB}_{5}$ : The religious leader of my community.

\section{3) Control Beliefs:}

$\mathrm{CB}_{1}$ : Preference for American products

$\mathrm{CB}_{2}$ : Dependence on American products

$\mathrm{CB}_{3}$ : Unavailability of substitutes to most of the American products at a reasonable price.

\section{Copyrights}

Copyright for this article is retained by the author(s), with first publication rights granted to the journal.

This is an open-access article distributed under the terms and conditions of the Creative Commons Attribution license (http://creativecommons.org/licenses/by/3.0/). 